\title{
Optimal conditions of natural and mixed convection in a vented rectangular cavity with a sinusoidal heated wall inside with a heated solid block
}

\author{
TEWFIK SEREIR $^{1 *}$, ABDELKRIM MISSOUM $^{1}$, BRAHIM MEBARKI $^{1}$, MOHAMED ELMIR $^{1}$, DOUHA MOHAMED $^{1}$ \\ Université Tahri Mohammed Béchar, B.P.417, Bechar 08000, Algeria
}

Abstract: - The present investigation deals with the natural, mixed and forced convection in a vented rectangular cavity having a sinusoidal heated vertical wall with a conducting solid block placed at one of the nine positions. The objective is to analyze numerically using finite element method the effects of the following parameters: inlet, outlet

positions, solid square positions, thermal coefficient $\lambda$, amplitude ratio $\varepsilon$, phase deviation $\phi$ and the solid square size on the thermo-convective flows. The Richardson number is varied from 0 to 40 , the Reynolds and Prandtl numbers are fixed respectively at 100 and 0.71 . To quantify the heat transfer of the solid block and to get closer to real conditions, we have developed a modification based on the evaluation of the Nusselt number using the average temperature in the cavity, unlike previous works which used the input temperature. As results, the sinusoidal temperature at the right wall gives higher heat transfer enhancement. The variation of the phase deviation and amplitude ratio have a slightly effect on the average fluid temperature and average Nusselt at the right wall and at the square solid.

Key-Words: - Mixed convection, Optimal position, Rectangular cavity, Solid block, finite element method.

Received: March 3, 2020. Revised: November 24, 2020. Accepted: December 15, 2020. Published: December 31, 2020.

\section{INTRODUCTION}

Natural, mixed and forced convection in rectangular spaces is an important subject of investigation, given its presence in various industrial applications such as: cooling of electronic components, heat losses in industrial systems. The mixed laminar convection regime in a ventilated rectangular cavity was already the subject of investigation by A. Raji and M. Hasnaoui [1]. A cavity vertical wall side is subjected to a constant heat flow, and the other walls are kept adiabatic. For Rayleigh numbers 103 and 106, and Reynolds numbers between 5 and 5000, they examine the thermal and dynamic field in order to propose correlation relationships. Heat transfer can be under both hot and cold temperatures between one of the vertical walls and the surrounding environment The natural and forced convection in laminar regime is of limited attraction due to the limited range of Rayleigh, and Reynolds values [2-3].Humphrey and To [4], had studied numerically the free and mixed turbulent convection of air, for a heated cavity with rectangular section at different orientations. They found that the details of natural convection are strongly governed by the characteristics of thematic transfers. These depend not only on the Grashof number, but also on the angle of inclination and cavity aspect ratio. To simulate the movement of air induced by a flame, Abib and Jaluria, [5] have placed a heat source in one of the lower corners of a rectangular cavity, this last one is equipped by a single opening towards the ambient environment. They found a cellular regime, characterized by a main recirculation zone in the lower part, and a weak counter-rotating cell near the upper wall. The same idea of placing a heat source in a cavity is also used by Papanicolau and Jaluria, [6] for a ventilated square cavity with adiabatic walls. By, fixing the Reynolds number at $\operatorname{Re}=103$ and $\mathrm{Re}=2.103$, the variation of the Richardson number following the variation of the Grashof number gave an oscillatory mode. A correlation relation which links the mean Nusselt number to the Richardson number and that of Grashof is proposed, this one is very close to that derived from turbulent natural convection in closed cavities. Roy and Basak, [7]Studied numerically natural convection with uniform heating on the bottom and the vertical wall , and also the non_uniform heating for different parameters $\operatorname{Pr}(0.2-100)^{-}$and $\mathrm{Ra}$ (103-106). Benderradji et al [8]studied the effect of the variation of the two parameters (Grashof and Reynolds) in laminar mixed convection inside a cubic cavity.Aidaoui et al [9] made a numerical investigation of the parameter affecting $3 \mathrm{D}$ in a rectangular channel at constant flux density for laminar convection flow regime using CFD code. Oronzio et al [10] have been made an experimental mixed convection investigation in a vented cavity with forced flow entering throw the heated vertical wall side (experimental mixed convection.). Biswas et al, [11] investigated heating element thermal management by dividing the heater into several identical segments under mixed convection for Ri (0.01-100), $\operatorname{Re}(50-200)$. Saha et al, [12] studied numerically forced and natural convection inside a rectangular enclosure with constant heating at bottom wall for $\operatorname{Pr}=0.71$, $\mathrm{Ri}(0-10) \mathrm{Re}$ $(50,100,200)$, as results and using Richardson, Reynolds and Nusselt Numbers, they developed an empirical correlation Saha et al, [13] investigated the mixed convection inside rectangular enclosure for different inlet and outlet opening placement configurations with constant heat source mount on right wall using finite element method. Satish and Mathur, [14] studied free and forced convection inside a rectangular enclosure with bottom heat source, for different ventilation arrangements. A numerically analyzed mixed convection in a complicated non-uniform (wavy walls) both side walls heated cavity using finite volume method with different parameters Richardson number (0.01-100), amplitude ratio $(0<\varepsilon<1)$, phase deviation $(0<\phi<\pi)$ for $\operatorname{Pr}=0.71$ was carried out by Mekroussi et al [15]. Rahman et al [16]studied mixed convection using finite element method inside a square cavity with inlet at the 
left edge of the vertical wall and top right vertical wall exit port. Changing some parameters as Ri, Re and Pr and also the inlet position.

In the literature, some investigation of the mixed convection in vented cavities were reported using different inlet and outlet ports location[17-20], uniform and non-uniform heated wall [21-24], adiabatic ,isothermal or heated solid block with different shape, size location and [25-33]. Gupta et al [34] studied a mixed convection in a ventilated cavity for different thermal conditions of the cavity walls with heated conducting cylinder at the size of $\mathrm{D}(0.1-0.5)$ and conductivity $\mathrm{K}(0.1-$ 10).Considering two cases of heated walls. First the vertical wall at the inlet side is considered hot while the other is cold and both horizontal walls are insulated. In the second case they consider hot bottom and cold top wall with insulated vertical walls.Rahman et al, [35] studied two dimensional mixed convection inside a ventilated cavity with central horizontal heated conducting circular solid for different cylinder size (0-0.6) and also Richardson number $0<\mathrm{Ri}<5$ using finite element method. As result, the phenomenon inside the cavity with or without cylinder depends on both the cylinder diameter and Ri number. Gupta et al [36] studied a double diffusive mixed convection for different aspect ratio and locations of the block inside a ventilated enclosure for different $\mathrm{Ri}, \mathrm{Re}$ and buoyancy ratio.House et al [37] Investigated natural convection with conducting body effect at the center of the enclosure . Lid driven cavity laminar mixed convection with an isothermal heated block inside, for different position, aspect ratio of the solid, Richardson number with the range (0.01-100) at fixed Reynolds and Prandtl numbers $\mathrm{Re}=100$ and $\mathrm{Pr}=0.71$ have been studied by Islam et al [38] .Rahman et al [39] investigated a mixed convection simulation in an enclosure with a heat generating body at $\operatorname{Re}(50,100,150$ and 200$), \operatorname{Pr}(0.71,1,3$ and 7.1$)$ and $\mathrm{Ri}(0,1$ and 5), with bottom vertical left wall inlet and top vertical right wall outlet port. Karimi et al [40] analyzed two dimensional mixed convection in an enclosures with adiabatic walls with two heated cylinders inside for different cylinder diameter, Reynolds and Richardson numbers with constant distance between cylinders. Rahman et al [41] investigated the laminar mixed convection in a square cavity with heated horizontal conducting square cylinder with heated right as results, the temperature and the flow field depend on the inner cylinder position and the Richardson number. Nahak et al, [42] made numerical analysis for mixed convection on an equilateral lid-driven triangular cavity with a circular cylinder at the center to study the effects of the position of the moving wall, cylinder geometry, aspect ratio $(\mathrm{AR}=\mathrm{D} / \mathrm{H})$, using finite volume method. Bouabdallah et al [43] numerically studied the turbulent mixed convection in a ventilated enclosure with middle heat source (different shapes and size) and two openings, using finite volume method at constant Grashof number $(\mathrm{Gr}=109)$ and different values of Richardson number. Al-Rashed et al, [44] made a three dimensional mixed convection simulation in ventilated cubical enclosure with nano-fluid and a central isothermal block. Some parameters used in this investigation as the block size and percentage of $\mathrm{A} 2 \mathrm{O} 3$ particles and $\mathrm{Ri}(0.01-100)$. Doghmi et al [45] investigate $3 \mathrm{D}$ mixed convection in two configurations for different inlet and outlet locations with an isothermally heated block inside a ventilated cavity for $0<\mathrm{Ri}<10$ and $50<\operatorname{Re}<100$ using finite volume method.
In this study, we carried out a number of parametrical variations: inlet, outlet, solid square different positions (P1 to P9), the conduction coefficient $\lambda$, amplitude ratio $\varepsilon$, phase deviation $\phi$ and the solid square different dimensions (lx,ly), the Reynolds number Re is kept fixed at 100 in order to found the optimal conditions where in which the heat transfer reach his higher values for different Richardson numbers.

\section{METHODOLOGY EQUATIONS \\ AND \\ GOVERNING}

Figure.1 shows a schematic diagram of the problem considered in the present study. The problem deals with a two-dimensional rectangular cavity with height $\mathrm{L}$, width 1.5 L, within which a heat conducting solid block with sides length $1 \mathrm{x}$, ly having a heat sources $\mathrm{q}=1$, thermal conductivity $\left(\lambda_{s}\right)$ located for nine different position. Three different cold $\left(\mathrm{T}_{\mathrm{i}}=0\right)$ inlet openings $(\mathrm{w})$ with uniform velocity $\left(\mathrm{u}_{\mathrm{i}}\right)$ located on the top of the cavity and also four different outlets $(\mathrm{w}=\mathrm{L} / 10)$ located on both vertical right and left walls .as shown in the Figure.1. The two horizontal and the left side walls are considered insulated and the right side vertical wall is assumed to have a periodical condition.

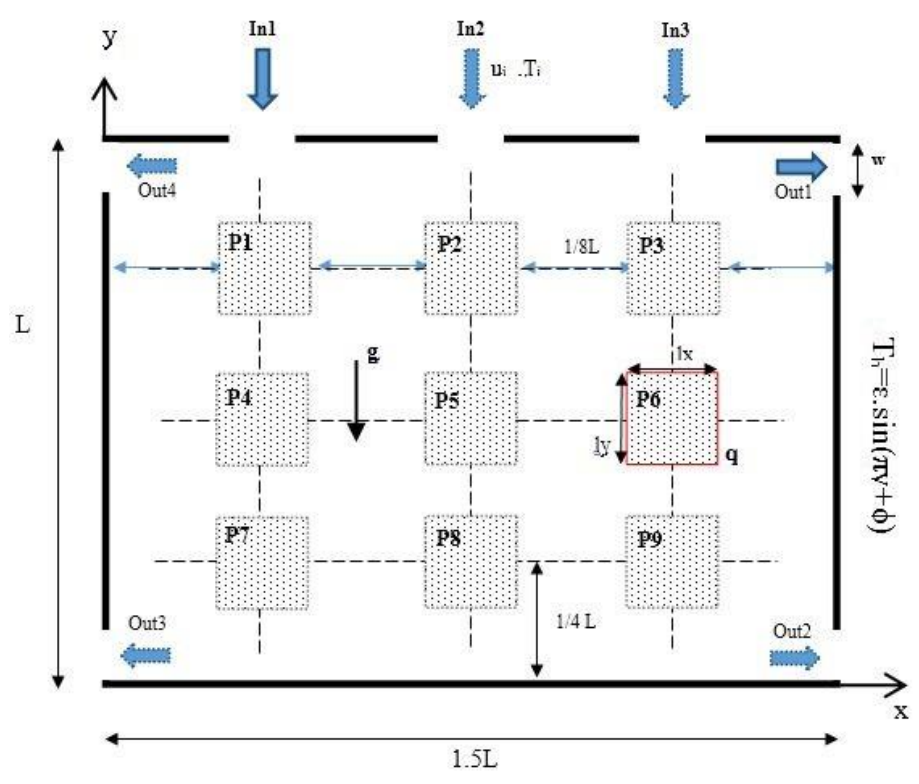

Figure 1. Schematic view of enclosure considered in the present study

The following assumptions are made: the flow is assumed to be two-dimensional Newtonian steady-state and viscous dissipation and compressibility effects are considered negligible in the present study and the gravity acts in the vertical downward, fluid properties are constant. The radiation heat exchange and the fluid density variations are neglected except in the buoyancy term.

The governing equations can be written in the dimensionless form:

$\frac{\partial \mathrm{U}}{\partial \mathrm{X}}+\frac{\partial \mathrm{V}}{\partial \mathrm{Y}}=0$ 


$$
\begin{aligned}
& \mathrm{U} \frac{\partial \mathrm{U}}{\partial \mathrm{X}}+\mathrm{V} \frac{\partial \mathrm{U}}{\partial \mathrm{Y}}=-\frac{\partial \mathrm{P}}{\partial \mathrm{X}}+\frac{1}{\operatorname{Re}}\left(\frac{\partial^{2} \mathrm{U}}{\partial \mathrm{X}^{2}}+\frac{\partial^{2} \mathrm{U}}{\partial \mathrm{Y}^{2}}\right) \\
& \mathrm{U} \frac{\partial \mathrm{V}}{\partial \mathrm{X}}+\mathrm{V} \frac{\partial \mathrm{V}}{\partial \mathrm{Y}}=-\frac{\partial \mathrm{P}}{\partial \mathrm{Y}}+\frac{1}{\operatorname{Re}}\left(\frac{\partial^{2} \mathrm{~V}}{\partial \mathrm{X}^{2}}+\frac{\partial^{2} \mathrm{~V}}{\partial \mathrm{Y}^{2}}\right)+\mathrm{Ri} \theta \\
& \mathrm{U} \frac{\partial \theta}{\partial \mathrm{X}}+\mathrm{V} \frac{\partial \theta}{\partial \mathrm{Y}}=\frac{1}{\operatorname{Re} \cdot \operatorname{Pr}}\left(\frac{\partial^{2} \theta}{\partial \mathrm{X}^{2}}+\frac{\partial^{2} \theta}{\partial \mathrm{Y}^{2}}\right)
\end{aligned}
$$

For the solid square, the energy equation is:

$$
0=\frac{\lambda}{\operatorname{Re} \cdot \operatorname{Pr}}\left(\frac{\partial^{2} \theta_{\mathrm{s}}}{\partial \mathrm{X}^{2}}+\frac{\partial^{2} \theta_{\mathrm{s}}}{\partial \mathrm{Y}^{2}}\right)
$$

The dimensionless variables are defined in the following form:

$$
\begin{aligned}
& \mathrm{X}=\frac{\mathrm{x}}{\mathrm{L}}, \mathrm{Y}=\frac{\mathrm{y}}{\mathrm{L}}, \mathrm{U}=\frac{\mathrm{u}}{\mathrm{u}_{\mathrm{i}}}, \mathrm{V}=\frac{\mathrm{v}}{\mathrm{u}_{\mathrm{i}}}, \mathrm{P}=\frac{\mathrm{p}}{\rho \mathrm{u}_{\mathrm{i}}{ }^{2}} \\
& \mathrm{~L}_{\mathrm{x}}=\frac{1_{\mathrm{x}}}{\mathrm{L}}, \mathrm{L}_{\mathrm{y}}=\frac{1_{\mathrm{y}}}{\mathrm{L}}, \theta=\frac{\left(\mathrm{T}-\mathrm{T}_{\mathrm{i}}\right)}{\left(\mathrm{T}_{\mathrm{h}}-\mathrm{T}_{\mathrm{i}}\right)}, \lambda=\frac{\lambda_{\mathrm{s}}}{\lambda_{\mathrm{f}}}
\end{aligned}
$$

Where $\mathrm{X}$ and $\mathrm{Y}$ represent the dimensionless horizontal and vertical direction respectively, $\mathrm{U}$ and $\mathrm{V}$ are the velocity components in the $\mathrm{X}$ and $\mathrm{Y}$ directions, $\mathrm{P}$ and $\mathrm{O}$ are respectively the dimensionless pressure, and temperature. The system equation is dimensionless in which the governing parameter are Prandtl number Pr, Richardson number Ri and the Reynolds number Re are defined as following

$$
\operatorname{Pr}=\frac{v}{\alpha}, \operatorname{Re}=\frac{\mathrm{U}_{0} \mathrm{~L}}{v} ; \operatorname{Ri}=\frac{\mathrm{Gr}}{\mathrm{Re}^{2}}, \mathrm{Gr}=\frac{g \beta \mathrm{L}^{3}\left(\mathrm{~T}_{\mathrm{h}}-\mathrm{T}_{\mathrm{i}}\right)}{v^{2}}
$$

\subsection{Boundary condition:}

The boundary conditions for this analysis are:

At the inlet: $U=0, V=1, \Theta=0$

At the outlet: convective Boundary Condition (CBC),

At all solid boundaries $=1$

At the right wall: periodical temperature: $T_{h}=\varepsilon \cdot \sin (\pi y+\phi)$ (add it as equation)

For the rest of adiabatic walls:

$$
\frac{\mathrm{dT}}{\mathrm{dX}}=0, \frac{\mathrm{dT}}{\mathrm{dY}}=0
$$

For the solid_fluid vertical interfaces of the block:

$$
\left(\frac{\mathrm{d} \theta}{\mathrm{dX}}\right)_{\text {fluid }}=\lambda\left(\frac{\mathrm{d} \theta_{\mathrm{s}}}{\mathrm{dX}}\right)_{\text {solid }}
$$

For the solid_fluid horizontal interfaces of the block:

$$
\left(\frac{\mathrm{d} \theta}{\mathrm{dY}}\right)_{\text {fluid }}=\lambda\left(\frac{\mathrm{d} \theta_{\mathrm{s}}}{\mathrm{dY}}\right)_{\text {solid }}
$$

\subsection{Heat and transfer calculation:}

The convective heat transfer coefficient within the rectangular cavity is evaluated in terms of the average Nusselt number at the right walls and the solid square as: For the right wall

$$
\mathrm{Nu}=\frac{1}{\mathrm{~L}_{\mathrm{h}}} \int_{0}^{\mathrm{L}_{\mathrm{h}}} \mathrm{Nu}(\mathrm{Y}) \mathrm{dY}
$$

With: $\mathrm{L}_{\mathrm{h}}=(\mathrm{L}-\mathrm{w})$

$\mathrm{L}_{h}$ is the length of the periodical temperature wall

For the solid:

We prefer to use the average temperature rather than the inlet temperature as in Saha et al [13] in order reach better results for the Nusselt number.

The square solid average Nusselt number :

$$
\begin{aligned}
\mathrm{Nu}_{\mathrm{S}} & =\frac{1}{\mathrm{~L}_{\mathrm{x}}} \int_{0}^{\mathrm{L}_{\mathrm{x}}} \mathrm{Nu}(\mathrm{x}) \mathrm{d} \eta+\frac{1}{\mathrm{~L}_{\mathrm{y}}} \int_{0}^{\mathrm{L}_{\mathrm{y}}} \mathrm{Nu}(\mathrm{y}) \mathrm{d} \eta \\
& =\frac{1}{\mathrm{~L}_{\mathrm{x}}} \int_{0}^{\mathrm{L}_{\mathrm{x}}} \frac{\mathrm{h} \cdot \mathrm{x}}{\lambda} \mathrm{dx}+\frac{1}{\mathrm{~L}_{\mathrm{y}}} \int_{0}^{\mathrm{Ly}} \frac{\mathrm{h} \cdot \mathrm{y}}{\lambda} \mathrm{dy}
\end{aligned}
$$

In major works the average Nusselt number is calculated based on the inlet temperature $\mathrm{T}_{0}$ as in saha [13] for our work we look for more improvement in order to get higher and more précises result in that case we calculate the average temperature inside the cavity and we finally get this equation:

$$
\mathrm{h}=\frac{\mathrm{q}}{\mathrm{T}-\theta_{\mathrm{av}}}
$$

The average temperature is defined as:

$$
\theta_{\mathrm{av}}=\frac{1}{\mathrm{~V}} \int \theta \mathrm{dV}
$$

Where $\mathrm{V}$ is the cavity volume.

\subsection{Numerical method}

The governing equations are numerically solved using a finite element method technique. Described by [46] and [47].A Direct (UMFPACK) linear system solver is used together with stationary non-linear solver ,the relative tolerance for the error is assumed to be 10-6.Non-uniform grids of triangular element are employed with denser grids clustering in regions near the heat source and the enclosure walls.

\subsection{Validation}

Our work has been validated against the work of Rahman et al [35] for mixed convection flow in a vented square cavity with a heat conducting square. We compared isotherms lines when the solid square was located at $l y=0.25$ and $1 x=0.5$ and the average Nusselt number when the solid square was located at $l y=1 x=0.5$ with the data of our results at $R e=100$, $\mathrm{Ri}=1.0, \lambda=5.0$ and $1 \mathrm{x}=1 \mathrm{y}=0.2$. We found that the present isotherms and the average Nusselt number are in good agreement with those of Rahman et al as shown in figure (1) and figure (2). 
WSEAS TRANSACTIONS on HEAT and MASS TRANSFER DOI: $10.37394 / 232012.2020 .15 .23$

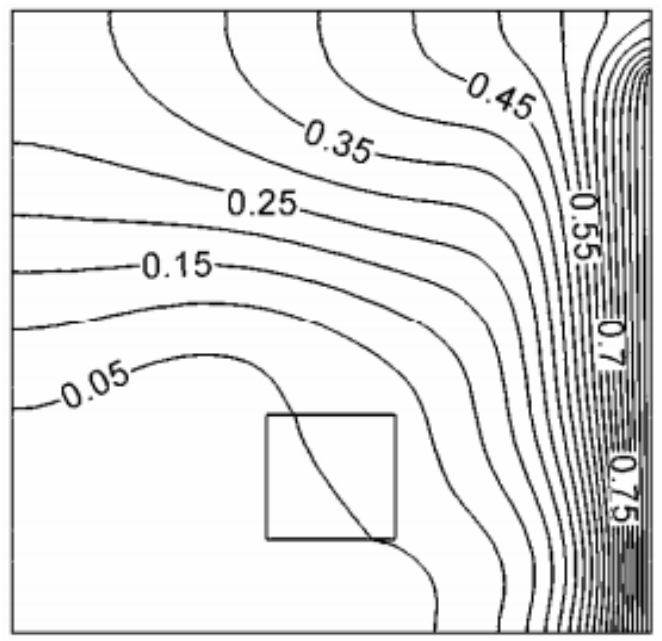

Rahman et al [35]

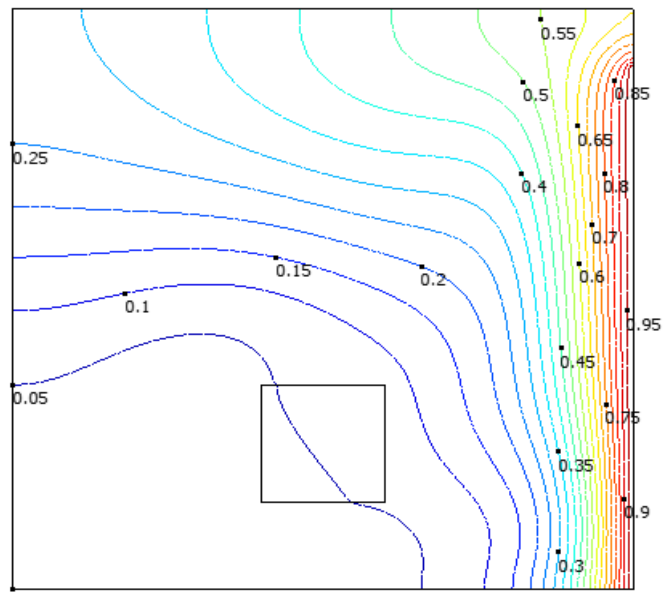

Present study
Tewfik Sereir, Abdelkrim Missoum,

Brahim Mebarki, Mohamed Elmir,

Douha Mohamed

Figure 3. Comparison of the Nusselt Number between the present results and those of [35] at $1 \mathrm{x}=0.5, \mathrm{ly}=0.25, \lambda=5$, $\mathrm{Re}=100$.

\subsection{Grid refinement check}

Several grids sizes of $8111,8943,9824,10700,11884$ and 12236 elements have been tested in the present simulation of Nusselt number at the periodical temperature surface as shown in (Table1). The finest grid size was 11884 elements; it provides more satisfaction results and less calculating time.

\begin{tabular}{|c|c|c|c|c|c|c|}
\hline Elements & 8111 & 8943 & 9824 & 10700 & 11884 & 12236 \\
\hline $\mathrm{Nu}$ & 47.5915 & 47.64686 & 47.678 & 47.7272 & 47.727 & 47,728 \\
\hline
\end{tabular}

Table 1. Grid sensivity Check at $\mathrm{Re}=100, \mathrm{Ri}=1.0, \lambda=5.0$, $\mathrm{d}=\mathrm{L} / 3, \mathrm{Lx}=1.5 / 2$ and $\mathrm{Ly}=0.5$.

\section{RESULTS AND DISCUSSION}

A numerical study is performed using finite element method for Two-dimensional laminar, mixed and forced convection in rectangular cavity contained a heat conducting solid square and periodical temperature at the right wall (0.9 L). The working fluid is chosen to be the Air with $\mathrm{Pr}=0.71$.some of the parametrical variations are carried out in this study as : inlet, outlet, solid square different positions (P1-...-P9), the conduction coefficient $\lambda$, amplitude ratio $\varepsilon$, phase deviation $\phi$ and the solid square different dimensions (lx, ly), the Reynolds number Re is kept fixed at 100 .

Figure 2. The Temperature contours between the present results and those of [35] at $\mathrm{Ri}=5, \mathrm{~lx}=0.5, \mathrm{ly}=0.25, \lambda=0.5$, $\mathrm{Re}=100$.

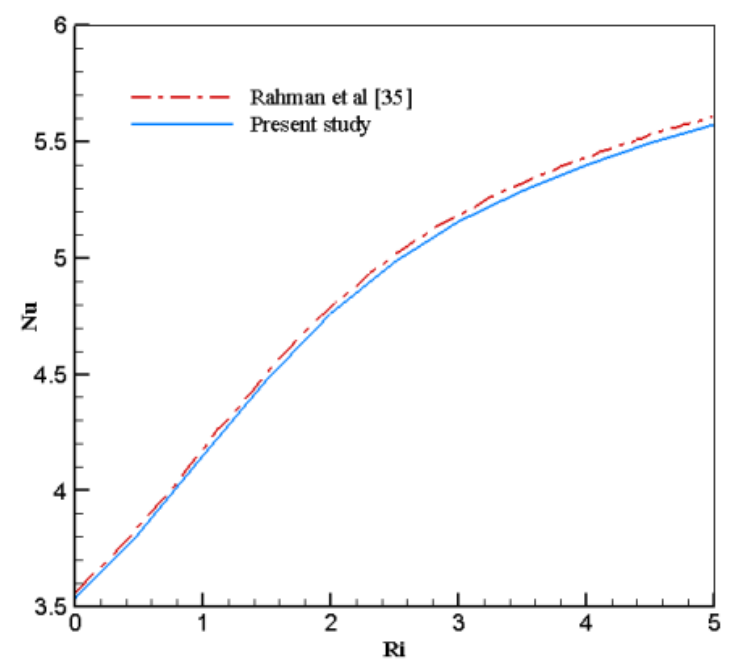


WSEAS TRANSACTIONS on HEAT and MASS TRANSFER DOI: $10.37394 / 232012.2020 .15 .23$

\begin{tabular}{|l|l|l|l|l|l|}
\hline \multicolumn{1}{|c|}{ Left in } & \multicolumn{1}{|c|}{$\mathrm{Nu}$} & \multicolumn{1}{|c}{ Middle in } & $\mathrm{Nu}$ & \multicolumn{1}{|c|}{ Right in } & \multicolumn{1}{|c|}{$\mathrm{Nu}$} \\
\hline In1-P1-out1 & 50.688 & In2-P1-out1 & 53.903 & In3-P1-out1 & 66.470 \\
\hline In1-P1-out2 & 72.374 & In2-P1-out2 & 64.962 & In3-P1-out2 & 65.576 \\
\hline In1-P1-out3 & 56.169 & In2-P1-out3 & 50.530 & In3-P1-out3 & 51.275 \\
\hline In1-P1-out4 & 37.224 & In2-P1-out4 & 11.112 & In3-P1-out4 & 10.083 \\
\hline In1-P2-out1 & 39.296 & In2-P2-out1 & 50.915 & In3-P2-out1 & 8.359 \\
\hline In1-P2-out2 & 75.167 & In2-P2-out2 & 74.919 & In3-P2-out2 & 64.804 \\
\hline In1-P2-out3 & 57.031 & In2-P2-out3 & 55.835 & In3-P2-out3 & 48.893 \\
\hline In1-P2-out4 & 63.088 & In2-P2-out4 & 40.830 & In3-P2-out4 & 23.532 \\
\hline In1-P3-out1 & 41.325 & In2-P3-out1 & 20.770 & In3-P3-out1 & 62.982 \\
\hline In1-P3-out2 & 78.433 & In2-P3-out2 & 76.432 & In3-P3-out2 & 71.265 \\
\hline In1-P3-out3 & 66.929 & In2-P3-out3 & 64.142 & In3-P3-out3 & 54.769 \\
\hline In1-P3-out4 & 73.222 & In2-P3-out4 & 65.341 & In3-P3-out4 & 47.628 \\
\hline In1-P4-out1 & 55.948 & In2-P4-out1 & 58.574 & In3-P4-out1 & 70.292 \\
\hline In1-P4-out2 & 68.561 & In2-P4-out2 & 66.305 & In3-P4-out2 & 65.630 \\
\hline In1-P4-out3 & 48.332 & In2-P4-out3 & 46.395 & In3-P4-out3 & 45.729 \\
\hline In1-P4-out4 & 31.878 & In2-P4-out4 & 14.066 & In3-P4-out4 & 12.980 \\
\hline In1-P5-out1 & 44.422 & In2-P5-out1 & 63.323 & In3-P5-out1 & 70.714 \\
\hline In1-P5-out2 & 79.651 & In2-P5-out2 & 68.882 & In3-P5-out2 & 65.906 \\
\hline
\end{tabular}

Tewfik Sereir, Abdelkrim Missoum,

Brahim Mebarki, Mohamed Elmir,

Douha Mohamed

\begin{tabular}{|l|l|l|l|l|l|}
\hline \multicolumn{1}{|c|}{ Left in } & \multicolumn{1}{|c|}{$\mathrm{Nu}$} & \multicolumn{1}{|c|}{ Middle in } & $\mathrm{Nu}$ & \multicolumn{1}{|c|}{ Right in } & \multicolumn{1}{c|}{$\mathrm{Nu}$} \\
\hline In1-P5-out3 & 58.679 & In2-P5-out3 & 47.411 & In3-P5-out3 & 44.929 \\
\hline In1-P5-out4 & 68.713 & In2-P5-out4 & 33.564 & In3-P5-out4 & 30.042 \\
\hline In1-P6-out1 & 55.463 & In2-P6-out1 & 55.091 & In3-P6-out1 & 76.853 \\
\hline In1-P6-out2 & 71.192 & In2-P6-out2 & 69.826 & In3-P6-out2 & 62.668 \\
\hline In1-P6-out3 & 68.572 & In2-P6-out3 & 66.205 & In3-P6-out3 & 41.212 \\
\hline In1-P6-out4 & 76.771 & In2-P6-out4 & 68.947 & In3-P6-out4 & 38.480 \\
\hline In1-P7-out1 & 60.332 & In2-P7-out1 & 60.332 & In3-P7-out1 & 71.214 \\
\hline In1-P7-out2 & 66.973 & In2-P7-out2 & 66.973 & In3-P7-out2 & 65.555 \\
\hline In1-P7-out3 & 29.149 & In2-P7-out3 & 16.904 & In3-P7-out3 & 15.980 \\
\hline In1-P7-out4 & 68.610 & In2-P7-out4 & 15.657 & In3-P7-out4 & 14.325 \\
\hline In1-P8-out1 & 52.494 & In2-P8-out1 & 59.820 & In3-P8-out1 & 71.437 \\
\hline In1-P8-out2 & 73.983 & In2-P8-out2 & 67.638 & In3-P8-out2 & 65.490 \\
\hline In1-P8-out3 & 56.685 & In2-P8-out3 & 53.174 & In3-P8-out3 & 18.028 \\
\hline In1-P8-out4 & 66.076 & In2-P8-out4 & 57.810 & In3-P8-out4 & 17.709 \\
\hline In1-P9-out1 & 74.663 & In2-P9-out1 & 76.840 & In3-P9-out1 & 74.662 \\
\hline In1-P9-out2 & 51.247 & In2-P9-out2 & 51.160 & In3-P9-out2 & 57.723 \\
\hline In1-P9-out3 & 66.963 & In2-P9-out3 & 66.963 & In3-P9-out3 & 32.122 \\
\hline In1-P9-out4 & 75.699 & In2-P9-out4 & 68.690 & In3-P9-out4 & 32.298 \\
\hline
\end{tabular}

Table 2. Average Nusselt number at $\mathrm{Re}=100, \mathrm{Ri}=1.0, \lambda=5.0$ and $\mathrm{L}_{\mathrm{x}}=\mathrm{L}_{\mathrm{y}}=\mathrm{L} / 3$
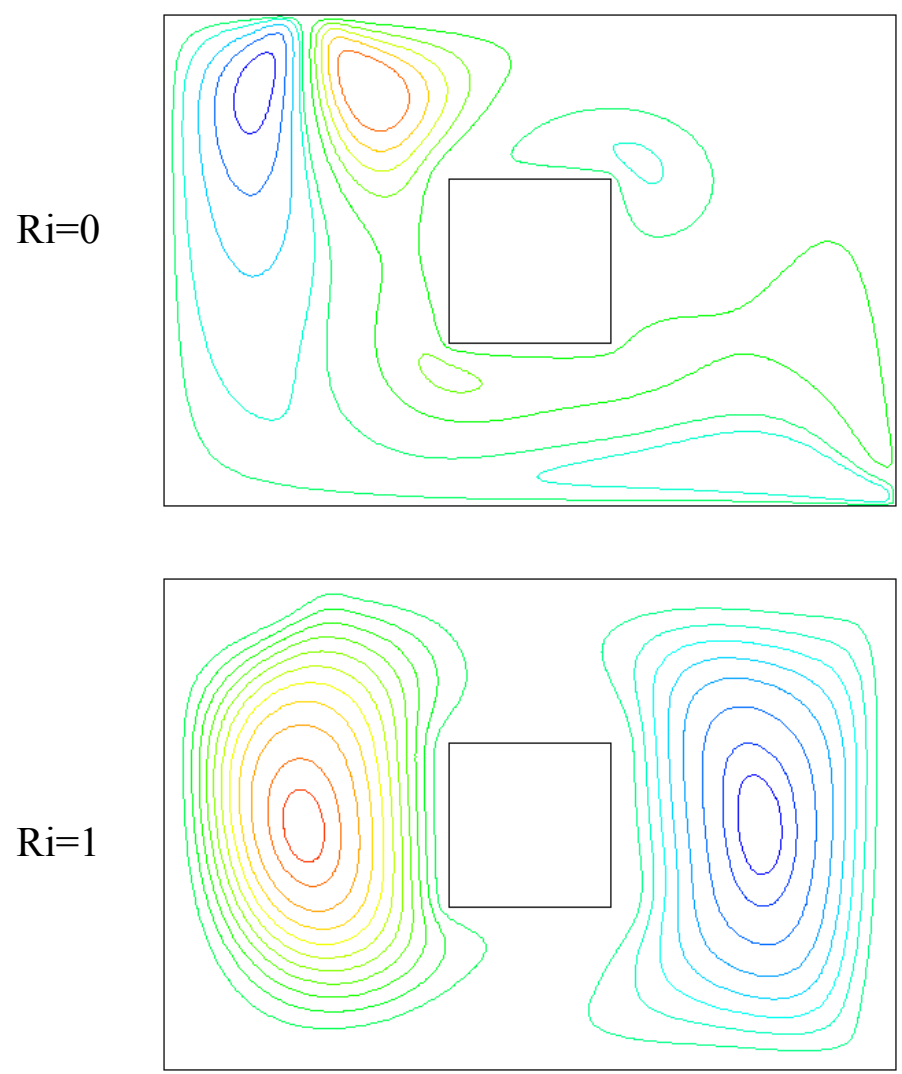
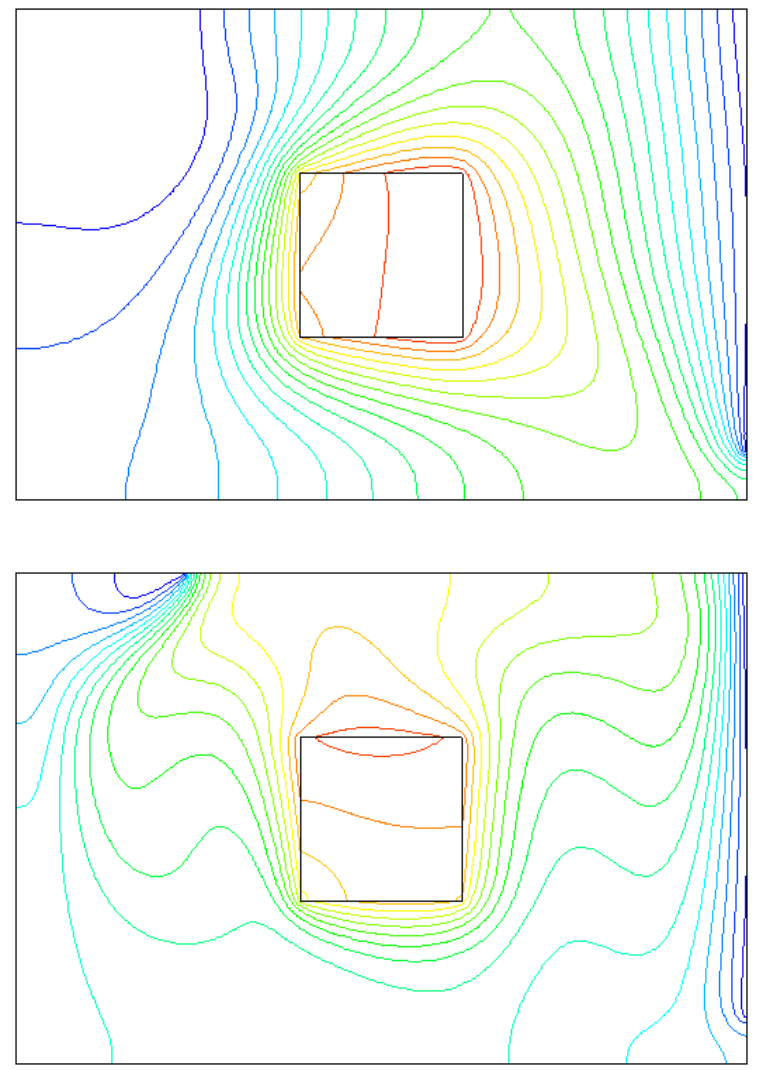

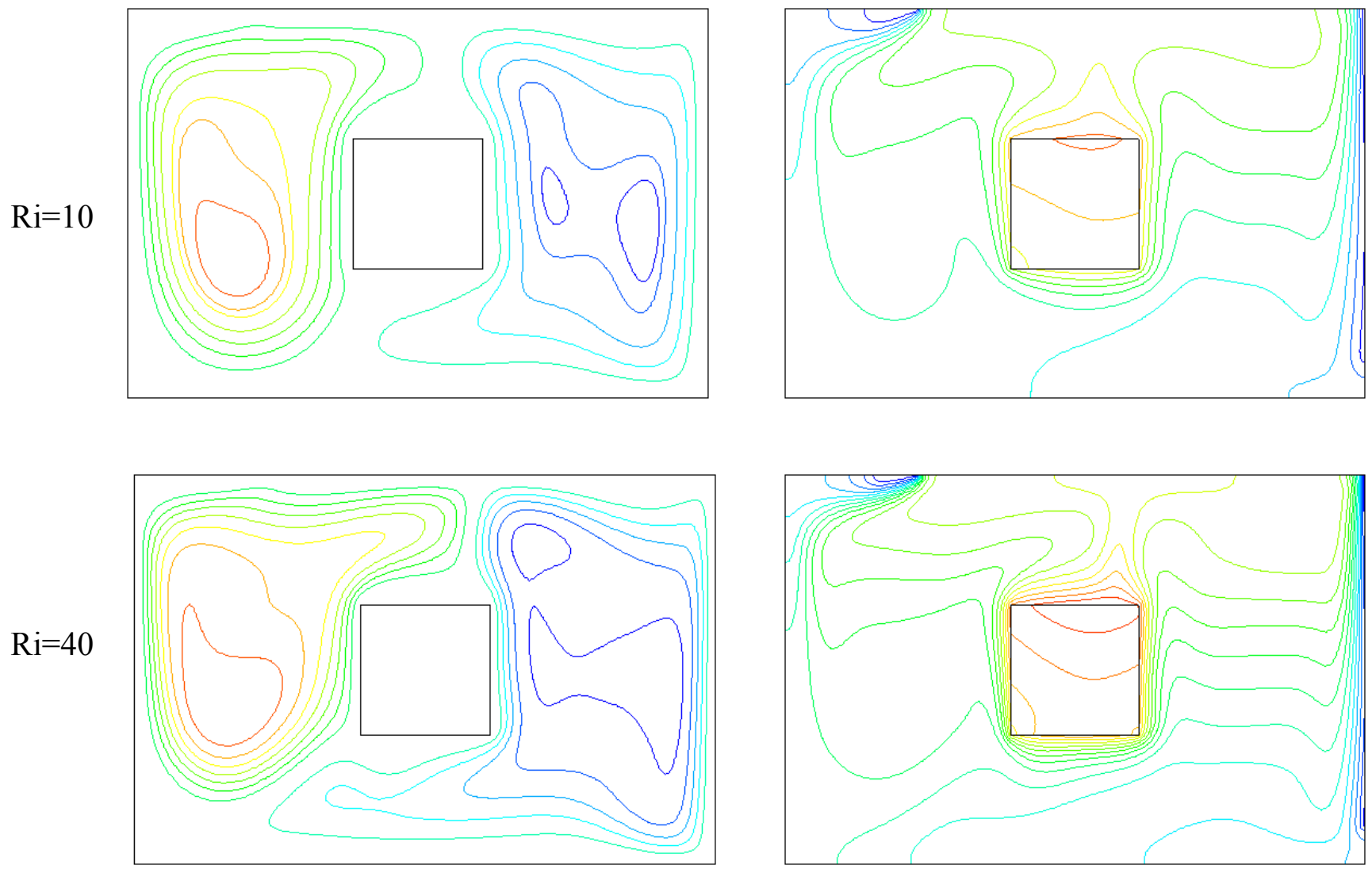

Figure 4.Variation of streamlines (left) and Isotherms (right) for the optimal position (In1-P5-out2) for different Richardson number.

The obtained results are presented in two sections. The first one focus on the fluid flow and the temperature distribution, and the second parts discuss firstly the effects of the following parameter: inlet, outlet, solid block positions, the conduction coefficient $\lambda$, amplitude ratio $\varepsilon$, phase deviation $\phi$ and the solid square different dimensions (lx,ly). Secondly the evaluating of heat transfer rate, namely: average Nusselt number at the right wall, the average fluid temperature and the solid square average Nusselt number.

In table2, the optimal and the most desirable configurations for different inlet, positions of the square solid and exit ports is (In1-P5-out2), that gives the highest values of the Nusselt number at the right wall.

We notice for figure. 3 at $\mathrm{Ri}=0$, the appearance of two symmetrical opposite directions vortices, near the inlet port. A clockwise direction vortex is developed near the inlet port at the top left corner of the rectangular cavity (the left side of the inlet port), which is expected since the air enters at the left of the top wall port (In1) and exit throw the bottom of the right wall (out2) and an anticlockwise direction vortex appears at the top wall at (the right side of the inlet port) and also two small vortices the first at the top right corner and the left bottom corner of the square solid. Forced convection dominates the major flow patterns from inlet to exit with too much penetration. It is seen that the anticlockwise direction vortex increases and the clockwise direction vortex diminishes and the left vortex disappear for $\mathrm{Ri}=1$.for $\mathrm{R} \mathrm{i}>1$ almost two symmetrical vortices appear at the right side and the left side of the square solid and as the Richardson number is getting higher the vortex also gets larger due to the effect of the natural convection and the conducting solid square on the flow patterns. From the isothermal contours, it is observed that the isotherms lines are clustered around the conducting square solid for different values of the Richardson number. It can be observed that there is some isothermal lines deviation on the right bottom corner of the conducting square solid for $\mathrm{Ri}=0$, this is due to the carried away and dissipated conducting square solid heat through the exit and the upper side of the conducting square solid for $\mathrm{Ri} \geq 1$ due to the dominating natural convection on the flow patterns and by this it is undoubtedly concluded that the higher-temperature region is concentrated at the upper wall of the conducting square solid.

\subsection{Effect of inlet position}

The variation of the inlet position port for different Ri number at $\operatorname{Pr}=0.71, \lambda=5, \varepsilon=1$ and $\phi=0$ for $(p=5)$ and out 2 is shown in figure 5 . The shape of the variation of the $\mathrm{Nu}$ number increases as the Richardson number increases. For inlet1 it is obviously that the $\mathrm{Nu}$ number decreases and takes higher values then the case of In2 and In 3 due to the impingement of the incoming air (In1) on the conducting square solid and the relative circulation of the mixing fluid 
inside the cavity. Therefore, higher heat transfer rates are obtained for out 1 at various Ri numbers. The Nusselt number is effected by both the inlet flow position and buoyancy force near the right wall.

The average temperature of the fluid decreases with the increasing of Richardson number for different inlet port positions. it is clearly seen that the temperature in the case of theinlet1 is lower than the case of $\operatorname{In} 2$ and $\operatorname{In} 3$ because the heat that was carried away from the conducting square solid for the case of In 1 is higher that the case of In 2 and In 3 due to the penetration and propagation of the incoming cold air inside the rectangular cavity, while for the In 2 and In 3 cases the incoming cold air is directly cooling the right wall of the rectangular cavity and directly send to the exit ,so the cold air has no time to propagate inside the cavity.

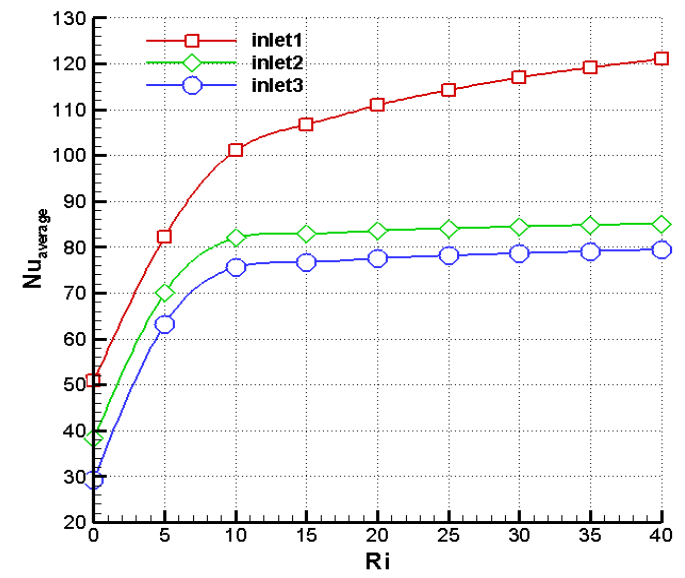

(a)

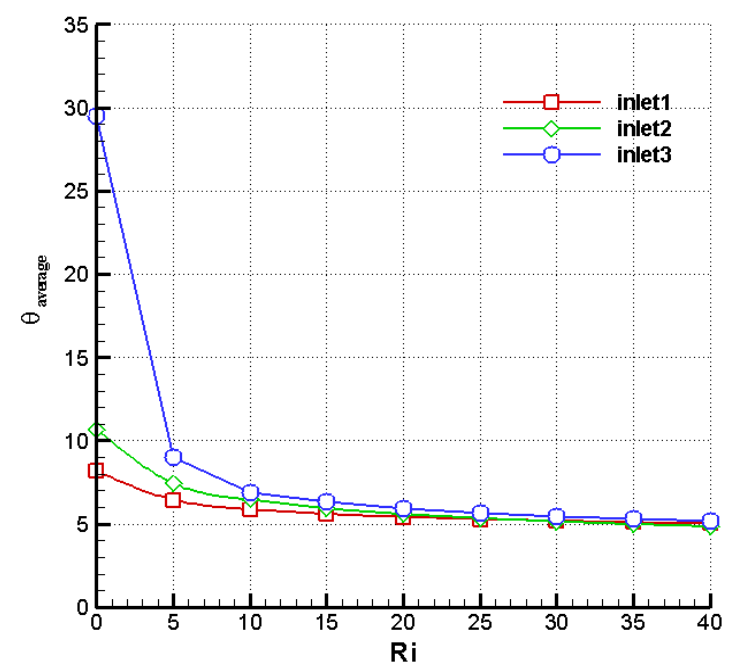

(b)
Douha Mohamed

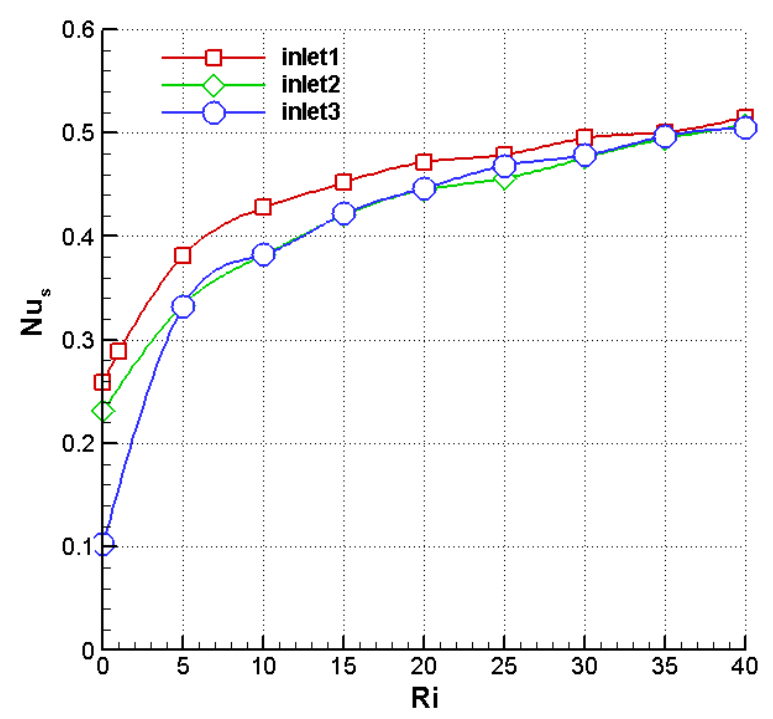

(c)

Figure 5.Effect of different inlet port positions on (a) the average Nusselt number for the right wall, (b) average fluid temperature and, (c) the solid square at different inlet port positions.

The $\mathrm{Nu}$ number for the solid square increases as $\mathrm{Ri}$ number increases. At $\mathrm{Ri}=0$, the $\mathrm{Nu}$ number of the solid square for inlet 2 and $\operatorname{In} 3$ is lower than the case of in 1 due to the effect of the periodical temperature on the heated conducting square solid.

\subsection{Effect of outlet position}

The variation of the outlet position for different Richardson numbers at $\operatorname{Pr}=0.71, \lambda=5, \varepsilon=1, \phi=0$, in 1 for optimal position (P5) are shown in figure below. It is clearly seen that the average Nusselt number for out 2 , out 3 and out 4 increases with the increasing of $\mathrm{Ri}$ number, while increasing then decreasing for the case of out 1 .

The fluid average temperature decreases with the increasing of $\mathrm{Ri}$ number while for out 1 for $\mathrm{Ri}<1$ the average temperature increases then decreases for $\mathrm{Ri}>1$.the Nusselt number for the solid square increases as $\mathrm{Ri}$ increases.

We found that the temperature decreases when the Richardson number increased, however for out1 it is observed that the results are lower that the case of out 2 , out 3 and out 4 du to incoming air that moves away from the inside to the outside of the cavity due to the forced convection and due to the recirculation due to natural convection.

When the Ri number is increased the average Nusselt number of the conducting square solid increases, we notice that higher value is shown for out1 due to higher convection coefficient near the conducting square solid walls. 


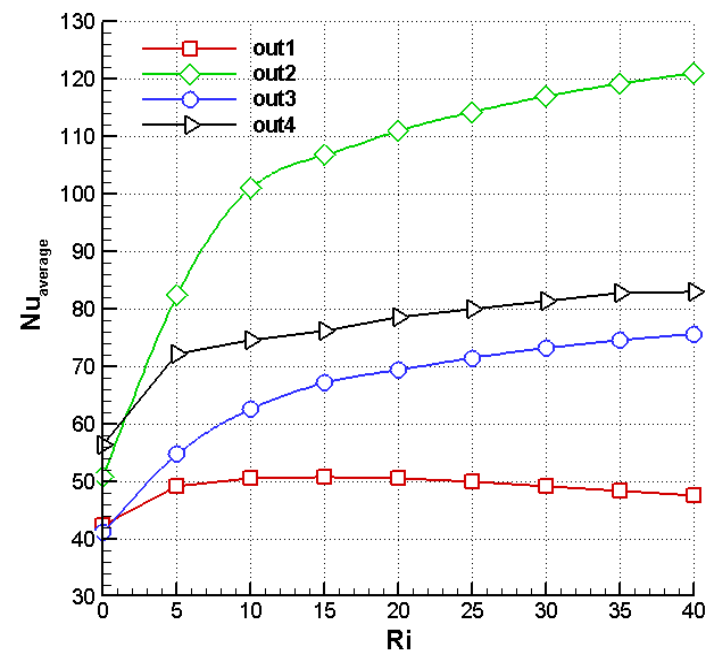

(a)

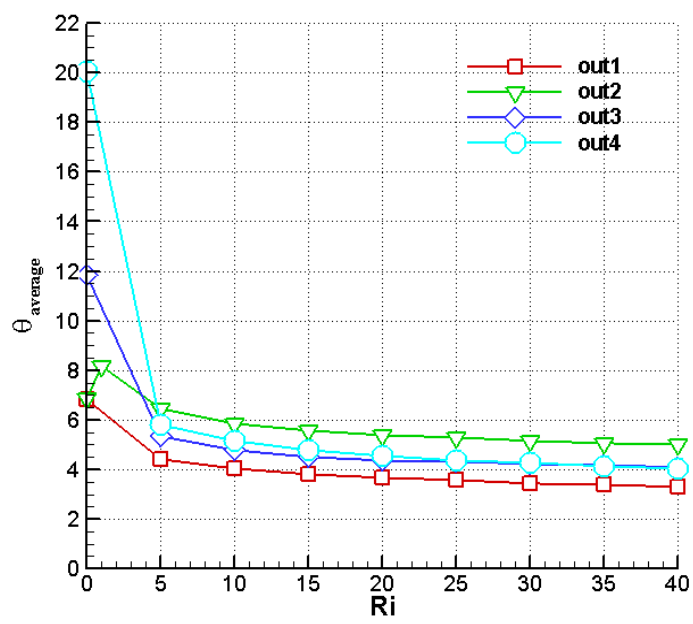

(b)

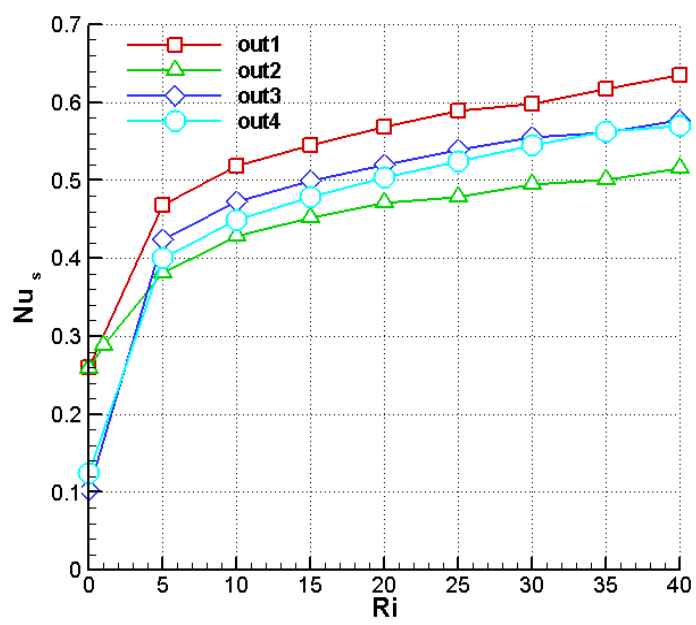

(c)

Figure 6. Average Nusselt number for different outlet positions, inlet1 fixed: (a) the average Nusselt number for the right wall, (b) average fluid temperature and, (c) the solid square at different inlet port positions

\subsection{Effect of amplitude ratio $\varepsilon$}

The variation of the amplitude ratio $\varepsilon$ for different $\mathrm{Ri}$ values at $\operatorname{Pr}=0.71, \lambda=5, \phi=0, \mathrm{In} 1$ and optimal position (P5) are shown in figure 7 below. We found that $\mathrm{Nu}$ number increases gradually with the increasing value of Richardson number. In the case of $\varepsilon=0$, the temperature at the right wall is steady and as the amplitude ratio is getting higher and the average Nusselt number is getting lower.

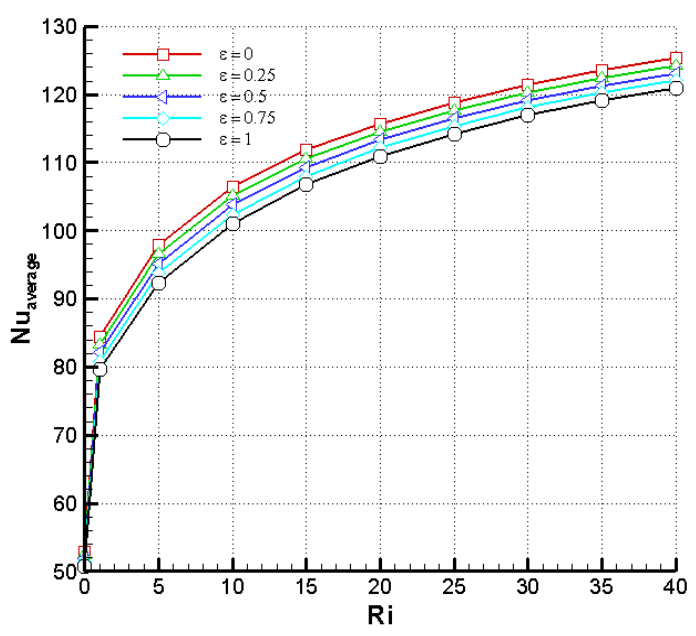

(a)

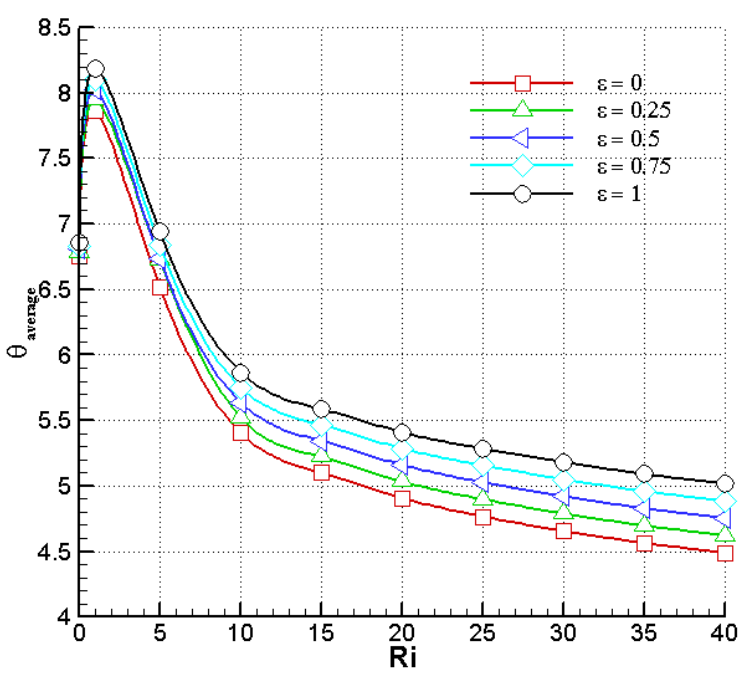

(b) 


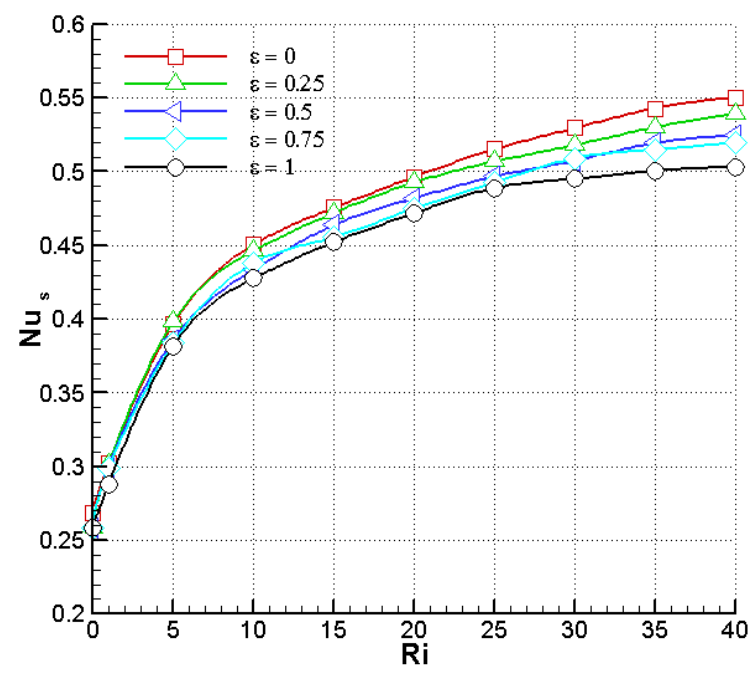

(c)

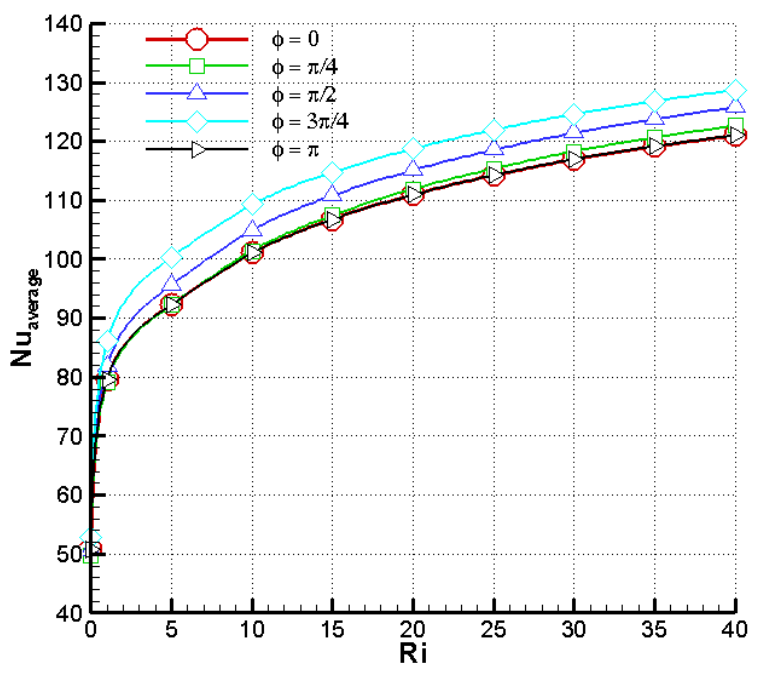

(a)

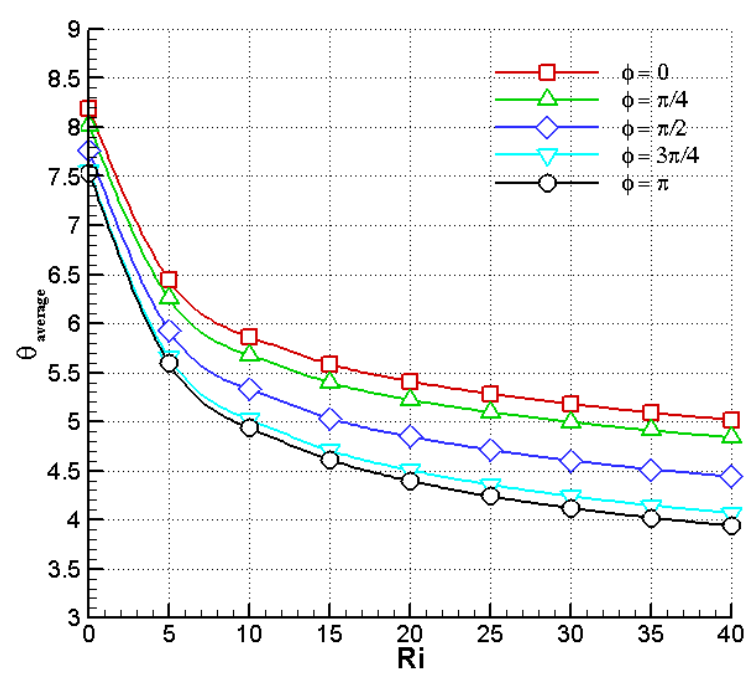

(b)

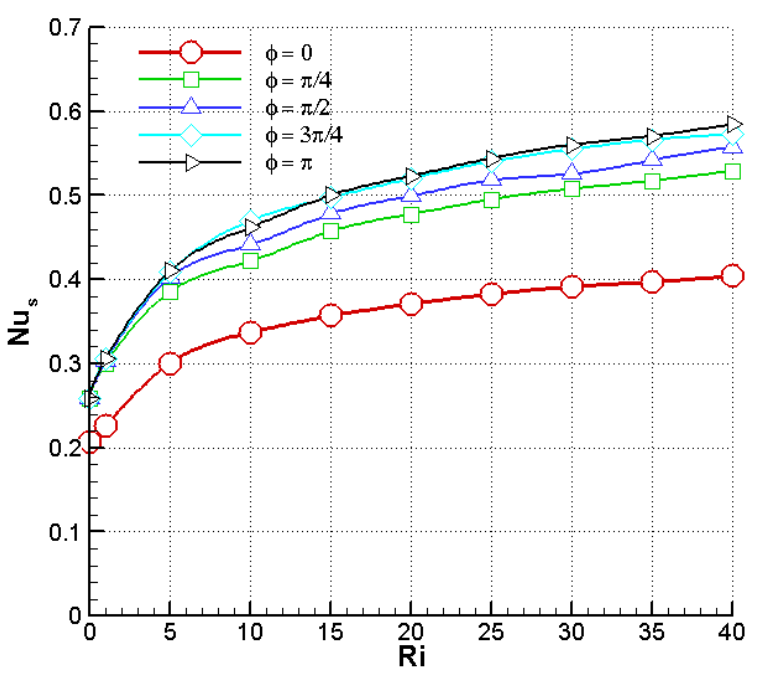

(c) 
Figure 8.Effect of phase deviation on (a) the average Nusselt number for the right wall, (b) average fluid temperature and,

(c) the solid square.

The increasing in Ri number augments the buoyancy effect and improves energy transportation which leads to increase in flow strength. The highest air evacuation is for $\phi=\pi$ and the lowest is for $\phi=0$. Phase deviation has a slightly effect on air evacuation in the rectangular cavity. Heating and cooling zone of the top and bottom of the right wall changed with variation of the phase deviation from 0 to $\pi$.this changing has an effect on the fluid velocity and air evacuation.

The Nusselt number for the solid square increases with the increasing of Ri number, it can be seen that the Nusselt number reach his highest values for $\phi=0$ and lowest values for $\phi=\pi$.we can see also that the marge between the results of Nusselt numbers decreases with the increasing phase deviation due to the effect of the temperature of the right wall of the rectangular cavity on the Nusselt number of the conducting square solid.

\subsection{Effect of thermal conductivity of the square solid}

The variation of the thermal conductivity for different $\mathrm{Ri}$ numbers at $\operatorname{Pr}=0.71, \varepsilon=1$ and $\phi=0$ are shown in figure 9 below. It is clear that the average $\mathrm{Nu}$ number at the right wall increases with the increasing of $\mathrm{Ri}$ number due to the increasing effect of natural convection. We notice also that as the Richardson number increases there was a slight variation on the result of Nusselt number for different value of $\lambda$. We conclude that the variation of thermal conductivity of the square solid has a slight effect on the Nu number

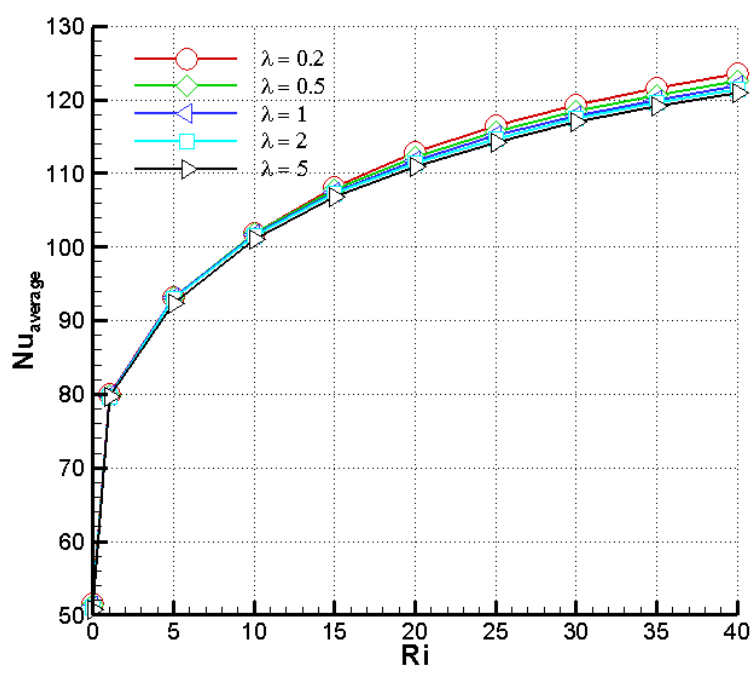

(a)

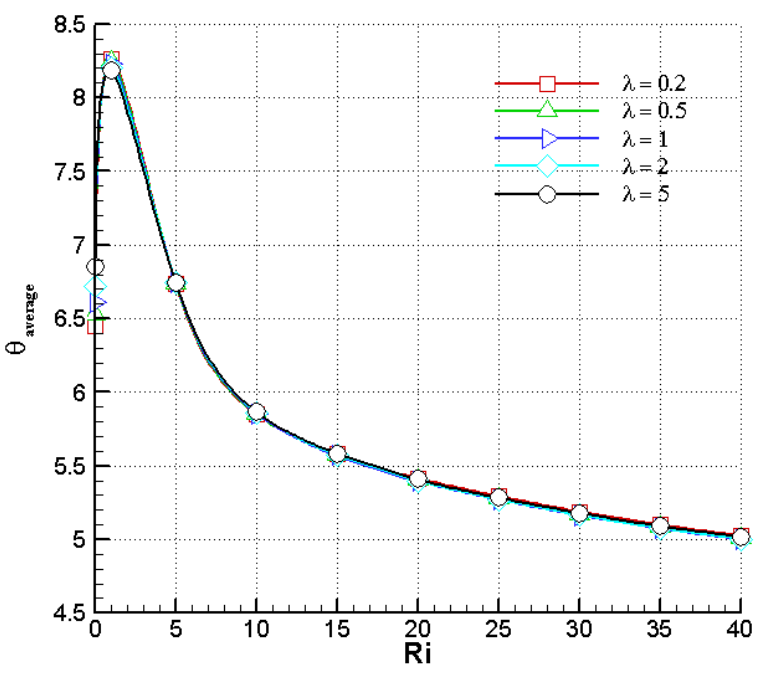

(b)

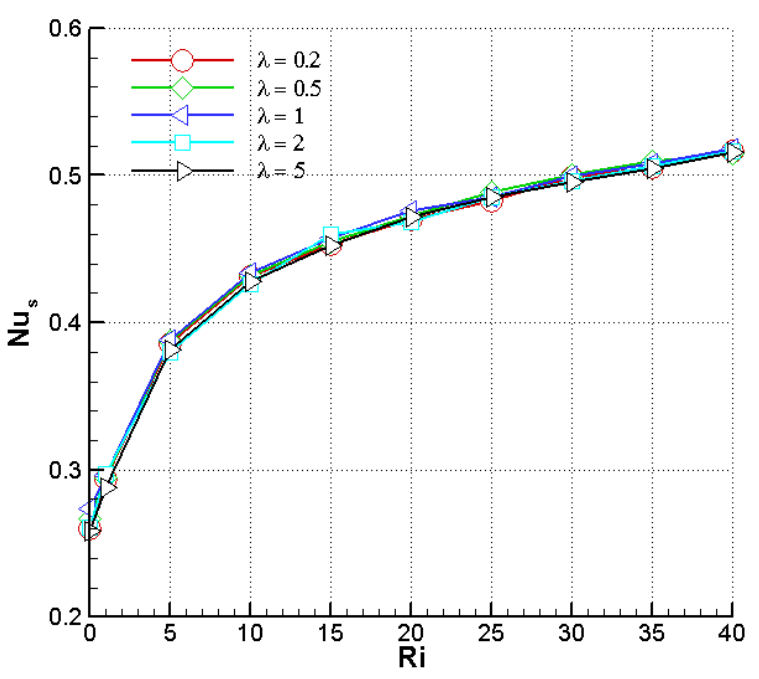

(c)

Figure 9. Effect of thermal conductivity on (a) the average Nusselt number for the right wall, (b) average fluid temperature and, (c) the solid square.

The average fluid temperature decreases with the increases $\mathrm{Ri}$ number for different values of thermal conductivity. From these results, we found out that the thermal conductivity has almost no effect on the temperature and air evacuation.

For the solid square, the average Nusselt number increases as $\mathrm{Ri}$ increases. The thermal conductivity has a very slight effect on the Nusselt number of the solid square. 


\subsection{Effect of square solid dimension}

The variation of the solid square dimensions for different Richardson numbers at $\operatorname{Pr}=0.71, \varepsilon=1, \phi=0$,In1 , and optimal position (P5) are shown in figure 10 below. The average Nusselt number increases with the increasing of Ri number. We note that as the square solid gets bigger the average Nusselt number gets higher. The contact surface between solid and fluid plays a major role in heat transfer.

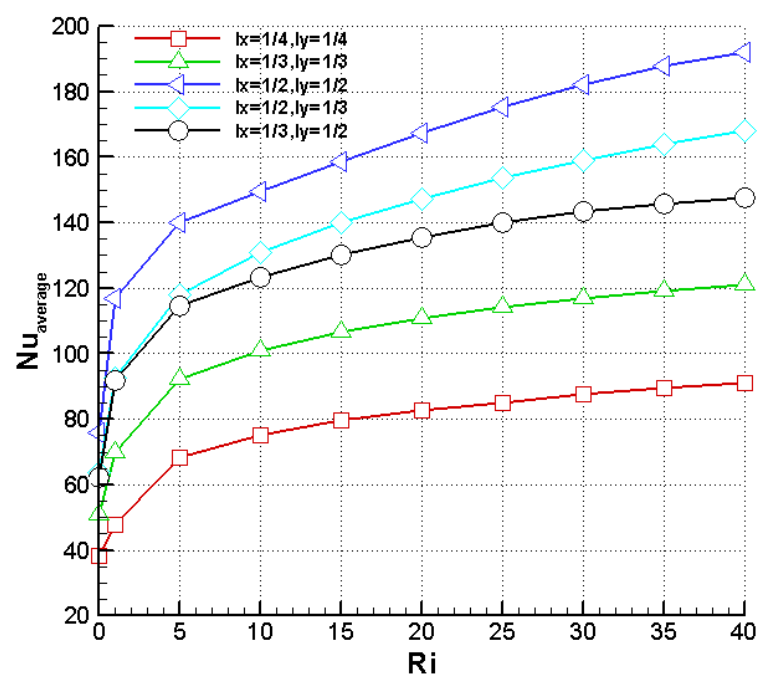

(a)

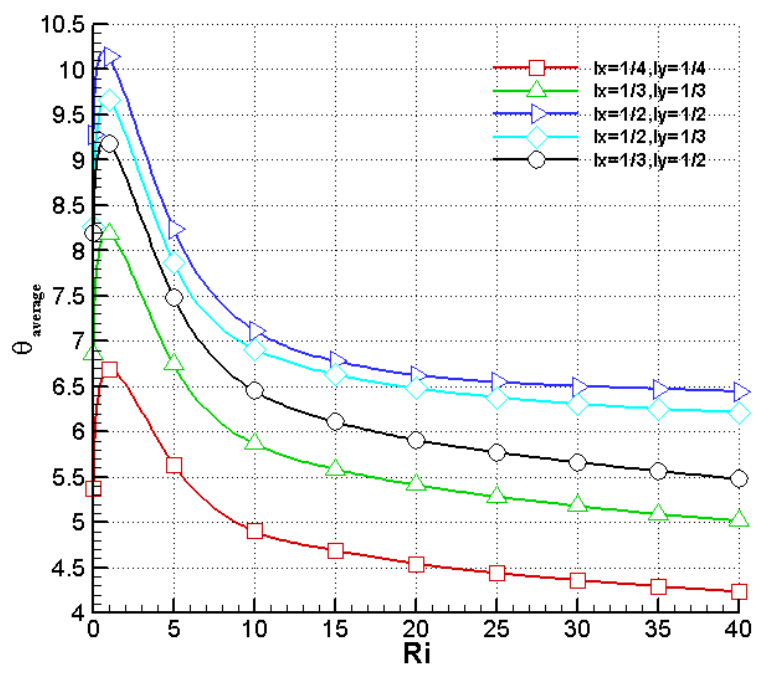

(b)

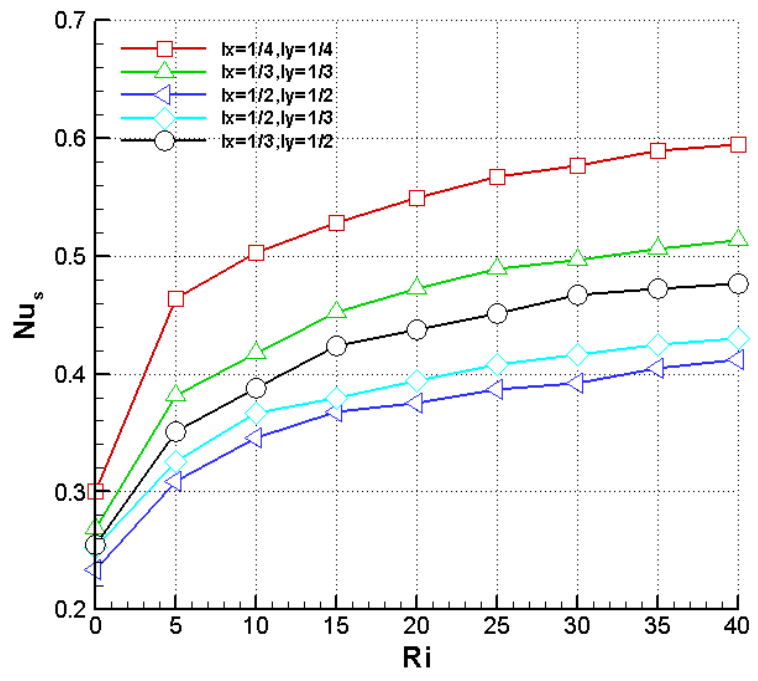

(c)

Figure 10. Effect of solid square dimensions on (a) the average Nusselt number for the right wall, (b) average fluid temperature and, (c) the solid square.

The average fluid temperature is decreases with the increases of Ri number. We notice that as the solid square gets bigger the average temperature of the rectangular cavity gets higher due to size of the square solid.

For the solid square, the average Nusselt number is increasing as Ri increases. The Nusselt numbers reach his highest values with the square solid at the smallest dimension. We can conclude that as the contact surface is increasing, it means losing heat rate also increases.

The results of the streamlines, isotherms, as well as the Nusselt number shows a good follow-up of curve and a very good agreement of results

\section{CONCLUSION}

A numerical investigation of mixed convection have been made inside a rectangular vented cavity with a heat conducting block and non-uniform heated right wall at different parameters. The objective of this work is to determine the optimal position that improve the heat transfer at $\operatorname{Re}=100$ and $\operatorname{Pr}=0.71$.

Highest Nusselt number values reached for the optimal position (In1-P5-out2) as shown in (table.2).

For different parameters ( inlet, outlet positions, solid square positions, thermal coefficient $\lambda$, amplitude ratio $\varepsilon$ and phase deviation $\phi$ and square solid dimension), we notice that the Nusselt numbers increases with the increasing value of the Richardson numbers and the average fluid temperature decreases with the increasing of the Richardson number. 
WSEAS TRANSACTIONS on HEAT and MASS TRANSFER DOI: 10.37394/232012.2020.15.23

- Thermal conductivity has a slightly effect on the average Nusselt number at the right wall, the solid square, and also the average fluid temperature.

- The variation of the phase deviation and amplitude ratio have a slightly effect on the average fluid temperature and average Nusselt at the right wall and square solid.

- Both average fluid temperature and Nusselt number at the right wall and the square solid highly depend on:

- Inlet and outlet positions;

- Dimension and position of solid block

\section{REFERENCES}

[1] Raji, A.; Hasnaoui, M. (1998). Corrélations en convection mixte dans des cavités ventilées, Revue Générale de Thermique, Vol. 37, No. 10,pp. 874-884. doi:10.1016/S0035-3159(98)80012-3

[2] Sefcik, D. M.; Webb, B. W.; Heaton, H. S. (1991). Analysis of natural convection in vertically-vented enclosures, International Journal of Heat and Mass Transfer, Vol. 34, No. 12,pp. 3037-3046. doi:10.1016/0017-9310(91)90073-N

[3] Yu, E.; Joshi, Y. (1997). A numerical study of threedimensional laminar natural convection in a vented enclosure, International Journal of Heat and Fluid Flow, Vol. 18, No. 6,pp. 600-612. doi:10.1016/S0142727X(97)00002-7

[4] Humphrey, J. A. C.; To, W. M. (1986). Numerical simulation of buoyant, turbulent flow-II. Free and mixed convection in a heated cavity, International Journal of Heat and Mass Transfer, Vol. 29, No. 4, pp. 593-610. doi:10.1016/0017-9310(86)90092-X

[5] Abib, A. H.; Jaluria, Y. (1992). Turbulent Penetrative and Recirculating Flow in a Compartment Fire, Heat and Mass Transfer in Fire and Combustion Systems, Vol. 223, pp.11-19. doi:10.1115/1.2836312

[6] Papanicolaou, E.; Jaluria, Y. (1995). Computation of Turbulent Flow in Mixed Convection in a Cavity With a Localized Heat Source, Journal of Heat Transfer, Vol. 117, No. 03, pp.649-658.doi:10.1115/1.2822626

[7] Roy, S.; Basak, T. (2005). Finite element analysis of natural convection flows in a square cavity with nonuniformly heated wall(s), International Journal of Engineering Science, Vol. 43, No. 8,pp. 668-680. doi:10.1016/j.ijengsci.2005.01.002

[8] Benderradji, R.; Gouidmi, H.; Taloub, D.; Beghidja, A. (2018). Numerical study three-dimensional of mixed convection in a cavity: Influence of Reynolds and Grashof numbers, Ournal of Advanced Research in Fluid Mechanics and Thermal Sciences, Vol. 51, No. 1, pp. 42-52

[9] Aidaoui, L.; Lasbet, Y.; Loubar, K. (2016). Numerical Analysis of the Parameters Governing 3D Laminar Mixed Convection Flow in a Rectangular Channel with Imposed Wall Flux Density, International Journal of
Heat and Technology, Vol. 34, No. 4,pp. 581-589. doi:10.18280/ijht.340405

[10] Manca, O.; Nardini, S.; Vafai, K. (2006). Experimental Investigation of Mixed Convection in a Channel With an Open Cavity, Experimental Heat Transfer, Vol. 19, No. 1,pp. 53-68. doi:10.1080/08916150500318380

[11] Biswas, N.; Mahapatra, P. S.; Manna, N. K. (2015). Thermal management of heating element in a ventilated enclosure, International Communications in Heat and Mass Transfer, Vol. 66,pp. 84-92. doi:10.1016/j.icheatmasstransfer.2015.05.018

[12] Saha, S.; Ali, M. (2006). Combined free and forced convection inside a two-dimensional multiple ventilated rectangular enclosure, Journal of Engineering and Applied Sciences, Vol. 1, No. 3, pp. 23-35

[13] Saha, S.; Mamun, A. H.; Hossein, M. Z.; SADR, A. A. K. M. (2008). Mixed convection in an enclosure with different inlet and exit configurations, Journa of Applied Fluid Mechanics, Vol. 01, No. 01, pp. 78-93

[14] Ajmera, S. K.; Mathur, A. N. (2015). Combined Free and Forced Convection in an Enclosure with different Ventilation Arrangements, Procedia Engineering, Vol. 127,pp. 1173-1180. doi:10.1016/j.proeng.2015.11.456

[15] Mekroussi, S.; Kherris, S.; Mebarki, B.; Benchatti, A. (2017). Mixed convection in complicated cavity with non-uniform heating on both sidewalls, International Journal of Heat and Technology, Vol. 35, No. 4,pp. 1023-1033. doi:10.18280/ijht.350439

[16] Rahman, M. M.; Alim, M. A.; Mamun, M. A. H.; Chowdhury, M. K.; Islam, A. K. M. S. (2007). Numerical Study of Opposing Mixed Convection in a Vented Enclosure, Journal of Engineering and Applied Sciences, Vol. 2, No. 2,pp. 25-36

[17] Saha, S.; Islam, M. T.; Ali, M.; Mamun, M. A. H.; Islam, M. Q. (2006). Effect of inlet and outlet locations on transverse mixed convection inside a vented enclosure, Journal of Mechanical Engineering, Vol. 36, pp. 27-37. doi:10.3329/jme.v36i0.808

[18] Mahmoudi, A. H.; Shahi, M.; Talebi, F. (2010). Effect of inlet and outlet location on the mixed convective cooling inside the ventilated cavity subjected to an external nanofluid, International Communications in Heat and Mass Transfer, Vol. 37, No. 8,pp. 1158-1173. doi:10.1016/j.icheatmasstransfer.2010.04.004

[19] Armaghani, T.; Talebi, F.; Mahmoudi, A. H.; Farzaneh Gord, M. (2014). The optimization of inlet and outlet port locations of a vented square cavity, Journal of Heat and Mass Transfer Research, Vol. 1, No. 1,pp. 35-45. doi:10.22075/JHMTR.2014.152

[20] Doghmi, H.; Abourida, B.; Belarche, L.; Sannad, M.; Ouzaouit, M. (2018). Effect of the inlet opening on mixed convection inside a 3-D ventilated cavity, Thermal Science, Vol. 22, No. 6A,pp. 2413-2424. doi:10.2298/TSCI170126121D

[21] Basak, T.; Roy, S.; Kumar, P.; Pop, I. (2009). Analysis of mixed convection flows within a square cavity with 
uniform and non-uniform heating of bottom wall, International Journal of Thermal Sciences, Vol. 48, No. 5, pp.891-912. doi:10.1016/j.ijthermalsci.2008.08.003

[22] Esfe, M. H.; Akbari, M.; Toghraie, D. S.; Karimipour, A.; Afrand, M. (2014). Effect of nanofluid variable properties on mixed convection flow and heat transfer in an inclined two-sided lid-driven cavity with sinusoidal heating on sidewalls, Heat Transfer Research, Vol. 45, No. 5, pp.409-432. doi:10.1615/HeatTransRes.2013007127

[23] Bouihi, I. El; Sehaqui, R. (2012). Numerical Study of Natural Convection in a Two-Dimensional Enclosure with a Sinusoidal Boundary Thermal Condition Utilizing Nanofluid, Vol. 4, No. 8, pp.445-452. doi:10.4236/eng.2012.48058

[24] Ismail, A.; Ahmed, B.; Abdelghani, R.; Mohammed, H.; Mohamed, N. (2018). Cooling enhancement by nanofluid mixed convection inside a horizontal vented cavity submitted to sinusoidal heating, Engineering Computations, Vol. 35, No. 4, pp.1747-1773. doi:10.1108/EC-03-2017-0080

[25] Bora, M. K.; Alam, M. F.; Sharma, B.; Barman, R. N. (2019). Numerical Investigation of Ag-H2O Nanofluid in a Lid Driven Square Cavity with Different Shaped Conducting and Insulating Cylinders Placed at Centre, International Journal of Heat and Technology, Vol. 37, No. 3, pp.831-838. doi:10.18280/ijht.370320

[26] Sheremet, M. A.; Oztop, H. F.; Pop, I.; Abu-hamdeh, N. (2015). Analysis of Entropy Generation in Natural Convection of Nanofluid inside a Square Cavity Having Hot Solid Block: Tiwari and Das' Model, Vol. 18, No. 1, pp.1-15. doi:10.3390/e18010009

[27] Rahman, M.; Alim, M. A.; Saha, S. (2010). MIXED CONVECTION IN A SQUARE CAVITY WITH A HEAT-CONDUCTING HORIZONTAL SQUARE CYLINDER., Suranaree Journal of Science \& Technology, Vol. 17, No. 2, pp.139-153

[28] Gangawane, K. M.; Manikandan, B. (2017). Mixed convection characteristics in lid-driven cavity containing heated triangular block, Chinese Journal of Chemical Engineering, Vol. 25, No. 10, pp.1381-1394. doi:10.1016/j.cjche.2017.03.009

[29] Gangawane, K. M.; Oztop, H. F.; Abu-hamdeh, N. (2018). Mixed convection characteristic in a lid-driven cavity containing heated triangular block: Effect of location and size of block, International Journal of Heat and Mass Transfer, Vol. 124, pp.860-875. doi:10.1016/j.ijheatmasstransfer.2018.03.079

[30] Alam, M. F.; Bora, M. K.; Sharma, B.; Barman, R. N. (2019). Numerical investigation of magnetohydrodynamics mixed convection in a square cavity for various shaped conducting obstacles placed at the center, Mathematical Modelling of Engineering Problems, Vol. 6, No. 4, pp.550-556. doi:10.18280/mmep.060410

[31] Sharma, B.; Kumar, B.; Barman, R. N. (2018). Numerical investigation of cu-water nanofluid in a differentially heated square cavity with conducting solid square cylinder at center, Vol. 36, No. 2, pp.714-722. doi:10.18280/ijht.360238

[32] Boutra A., Ragui K., Labsi N., B. Y. K. (2017). Free convection enhancement within a nanofluid' filled enclosure with square heaters, Vol. 35, No. 3, pp.447458. doi:10.18280/ijht.350302

[33] Zou, J.F. , Gao, Y. , Chow, W. K. (2010). Numerical simulations on laminar natural convection in a square cavity with a conducting circular block, International Journal of Heat and Technology, Vol. 28, No. 1, pp.1-8. doi:DOI: $10.18280 / \mathrm{ijht} 280101$

[34] Gupta, S. K.; Chatterjee, D.; Monda, B. (2015). Investigation of mixed convection in a ventilated cavity in the presence of a heat conducting circular cylinder, Numerical Heat Transfer; Part A: Applications, Vol. 67, No. 2, pp.52-74. doi:10.1080/10407782.2014.916113

[35] Rahman, M.; Alim, M. A.; Saha, S.; Chowdhury, M. K. (2008). Mixed convection in a vented square cavity with a heat conducting horizontal solid circular cylinder, Journal of Naval Architecture and Marine Engineering, Vol. 5, No. 2, 37-46

[36] Gupta, N.; Nayak, A. K.; Malik, S. (2018). Conjugate heat and species transport in an air filled ventilated enclosure with a thermo-contaminated block, International Journal of Heat and Mass Transfer, Vol. 117 , $388-411$ doi:10.1016/j.ijheatmasstransfer.2017.10.028

[37] House, J. M.; Beckermann, C.; Smith, T. E. (1990). Effect of a centered conducting body on natural convection heat transfer in an enclosure, Numerical Heat Transfer; Part A: Applications, Vol. 18, No. 2, 213-225. doi:10.1080/10407789008944791

[38] Islam, A. W.; Sharif, M. A. R.; Carlson, E. S. (2012). Mixed convection in a lid driven square cavity with an isothermally heated square blockage inside, International Journal of Heat and Mass Transfer, Vol. 55, Nos. 19-20, pp.5244-5255. doi:10.1016/j.ijheatmasstransfer.2012.05.032

[39] Rahman, M. M.; Parvin, S.; Rahim, N. A.; Islam, M. R.; Saidur, R.; Hasanuzzaman, M. (2012). Effects of Reynolds and Prandtl number on mixed convection in a ventilated cavity with a heat-generating solid circular block, Applied Mathematical Modelling, Vol. 36, No. 5, pp.2056-2066. doi:10.1016/j.apm.2011.08.014

[40] Karimi, F.; Xu, H.; Wang, Z.; Yang, M.; Zhang, Y. (2016). Numerical simulation of steady mixed convection around two heated circular cylinders in a square enclosure, Heat Transfer Engineering, Vol. 37, No. 1, pp.64-75. doi:10.1080/01457632.2015.1042343

[41] Rahman, M. M.; Alim, M. A.; Saha, S.; Chowdhury, M. K. (2008). A numerical study of mixed convection in a square cavity with a heat conducting square cylinder at different locations, Journal of Mechanical Engineering, Vol. 39, No. 2, 2 pp.78-85. doi:https://doi.org/10.3329/jme.v39i2.1850

[42] Nahak M.P., Triveni M.K., P. R. (2017). Numerical 
investigation of mixed convection in a lid-driven triangular cavity with a circular cylinder using ANN modeling, International Journal of Heat and Technology, Vol. 35, No. 4, pp.903-918. doi:10.18280/ijht.350427

[43] Bouabdallah S, Chati D, Ghernaout B., Atia A, L. A. (2016). Turbulent mixed convection in enclosure containing a circular/square heat source, International Journal of Heat and Technology, Vol. 34, No. 3, pp.446-454. doi:10.18280/ijht.340314

[44] Al-Rashed, A. A. A. A.; Kalidasan, K.; Kolsi, L.; Velkennedy, R.; Aydi, A.; Hussein, A. K.; Malekshah, E. H. (2018). Mixed convection and entropy generation in a nanofluid filled cubical open cavity with a central isothermal block, International Journal of Mechanical Sciences, Vol. 135, 362-375. doi:10.1016/j.jimecsci.2017.11.033

[45] Doghmi, H.; Abourida, B.; Belarche, L.; Sannad, M.; Ouzaouit, M. (2018). Numerical study of mixed convection inside a three-dimensional ventilated cavity in the presence of an isothermal heating block, International Journal of Heat and Technology, Vol. 36, No. 2, 447-456. doi:10.18280/ijht.360209

[46] Taylor, C.; Hood, P. (1973). A numerical solution of the Navier-Stokes equations using the finite element technique, Computers and Fluids, Vol. 1, No. 1, pp.73100. doi:10.1016/0045-7930(73)90027-3

[47] Dechaumphai, P. (1999). Finite Element Method in Engineering, Chulalongkorn University Press, Bangkok

\section{NOMENCLATURE}

Solid block side length

Pr Prandtl number

$\mathrm{Re} \quad$ Reynolds number

Ri Richardson number

Gr Grashof number

$\mathrm{L}_{\mathrm{x}}, \mathrm{L}_{\mathrm{y}} \quad$ dimensionless solid block length

g

$\mathrm{Nu}$

$\mathrm{W}$

U,V

$\mathrm{U}, \mathrm{V}$

$\mathrm{x}, \mathrm{y} \quad$ cartesian coordinates, $\mathrm{m}$

$\mathrm{X}, \mathrm{Y} \quad$ dimensionless coordinate

$\mathrm{p}$

$\mathrm{P}$

$\mathrm{T}$

Pressure, $\mathrm{KPa}$

Dimensionless pressure

dimensional temperature $(K)$

heat source at solid boundaries

\section{Greek symbols}

$\begin{array}{ll}\alpha & \text { thermal diffusivity, } \mathrm{m}^{2} \cdot \mathrm{s}^{-1} \\ \beta & \text { thermal expansion coefficient, } \mathrm{K}^{-1} \\ \Theta & \text { dimensionless temperature } \\ \mu & \text { dynamic viscosity, } \mathrm{kg} \cdot \mathrm{m}^{-1} \cdot \mathrm{s}^{-1} \\ \rho & \text { Density, } \mathrm{kg} \cdot \mathrm{m}^{-2} \\ \phi & \text { phase deviation } \\ \varepsilon & \text { amplitude ratio } \\ \lambda & \text { Dimensionless thermal conductivity } \\ v & \text { Kinematic viscosity, } \mathrm{m}^{2} \cdot \mathrm{s}\end{array}$

Subscripts

$\begin{array}{ll}\text { avg } & \text { nanoparticle } \\ \mathrm{f} & \text { fluid (pure water) } \\ \mathrm{s} & \text { solid } \\ \mathrm{i} & \text { inlet state } \\ \mathrm{h} & \text { hot }\end{array}$

\section{Creative Commons Attribution License 4.0 (Attribution 4.0 International, CC BY 4.0)}

This article is published under the terms of the Creative Commons Attribution License 4.0 https://creativecommons.org/licenses/by/4.0/deed.en US 